\title{
COMPOSIÇÃO E ABUNDÂNCIA DO ZOOPLÂNCTON EM UM CÓRREGO URBANO
}

\author{
Renata Martins dos Santos ${ }^{1}$
}

Raquel Aparecida Moreira ${ }^{2}$

Odete Rocha ${ }^{3}$

Resumo: O conhecimento das espécies zooplanctônicas tem sido um poderoso instrumento para avaliar modificações nos ecossistemas aquáticos, os quais são submetidos a grandes impactos causados pelas atividades antrópicas. A distribuição e estrutura do zooplâncton em ecossistemas de água doce são influenciadas pelo tipo de habitat e pela estabilidade no ambiente. Este rápido inventário tem como objetivo analisar a comunidade zooplanctônica que caracteriza o córrego Santa Maria do Leme no município de São Carlos, SP a fim de complementar a avaliação da qualidade da água e detectar os efeitos de ambientes lóticos sobre esta comunidade. Foram registradas as medidas da temperatura da água, $\mathrm{pH}$, condutividade e oxigênio dissolvido. $\mathrm{O}$ zooplâncton foi amostrado com rede de plâncton $(68 \mu \mathrm{m})$. As amostras foram fixadas com formol na concentração final $4 \%$ e os organismos foram identificados e contados, calculando-se então a densidade e os índices de diversidade, dominância e equitabilidade. Foram identificadas 18 espécies, sendo que para Protozoa e Meroplâncton foi registrada a maior riqueza (seis espécies cada); para Rotifera registrou-se três espécies, Cladocera (duas espécies) e Copepoda (um táxon). A análise da comunidade zooplanctônica entre os pontos no córrego Santa Maria do Leme revelou um padrão diferenciado na abundância e

\footnotetext{
${ }^{1}$ Bióloga, Programa de Pós-Gradução em Ecologia e Recursos Naturais, Universidade Federal de São Carlos. renata cordis@yahoo.com.br

${ }^{2}$ Bióloga, Programa de Pós-Gradução em Ecologia e Recursos Naturais, Universidade Federal de São Carlos. raquel.moreira88@hotmail.com

${ }^{3}$ Bióloga, Programa de Pós-Gradução em Ecologia e Recursos Naturais, Universidade Federal de São Carlos. doro@ufscar.br
} 
diversidade de espécies, sendo a densidade e a riqueza de espécies maiores no ponto P1. Os protozoários e rotíferos dominaram tanto em termos de riqueza quanto de densidade. O micro-hábitat proporcionado pela instabilidade dos locais garantiu uma maior quantidade de matéria orgânica em suspensão, favorecendo o microzooplâncton.

Palavras-chave: Córrego urbano. Degradação. Diversidade de espécies.

\section{Introdução}

Os ecossistemas aquáticos continentais foram e ainda são submetidos a grandes impactos causados pelas atividades antrópicas desenvolvidas em seu entorno, e geralmente a qualidade de suas águas está intimamente ligada às condições econômicas e de saneamento dos grandes centros. A gestão destes ambientes constitui um grande desafio para administradores e tomadores de decisão em diferentes esferas do poder municipal ou estadual. Nas últimas décadas os estudos das comunidades aquáticas têm sido incluídos nos protocolos de avaliação de impactos ambientais e dentre estas a comunidade zooplanctônica tem sido frequentemente utilizada.

O conhecimento das espécies zooplanctônicas tem sido um poderoso instrumento para avaliar modificações causadas nos ecossistemas aquáticos por várias atividades impactantes como introdução de espécies exóticas, assoreamento e contaminação por esgotos domésticos e industriais, desmatamento entre outras. O zooplâncton, um dos grupos de invertebrados mais abundantes nas águas doces, tem sido estudado em vários ambientes do Brasil (SANTOS-WISNIEWISKI et al., 2002; SANTOS et al., 2009; NEGREIROS et al., 2009).

Os invertebrados aquáticos, apesar de seu destacado papel ecológico, ainda assim têm sido pouco considerados na elaboração de planos de manejo e conservação, devido sobretudo à dificuldade de identificação das espécies. Isso, por sua vez, decorre do reduzido número de taxonomistas, das dificuldades de amostragem em regiões de difícil acesso e da falta de equipamentos adequados para a realização de pesquisas (MAIABARBOSA et al., 2006) .

Os organismos pertencentes ao zooplâncton se destacam pela enorme riqueza de espécies, têm grande importância ecológica, pois participam ativamente de processos 
responsáveis pelo funcionamento dos ecossistemas - como ciclagem de nutrientes e manutenção das cadeias tróficas e são considerados como um compartimento estratégico na dissipação energética dos ecossistemas aquáticos e na manutenção e orientação das teias tróficas aquáticas (ROCHE; ROCHA, 2005). Em função do rápido ciclo de vida, as alterações ocorridas na comunidade fitoplanctônica são rapidamente espelhadas pelo zooplâncton, que passa a sinalizar a intensidade e as condições estabelecidas durante e após a consolidação destas perturbações. Além disso, o zooplâncton também apresenta forte vinculação com os níveis tróficos mais elevados da teia trófica aquática (SORANNO et al., 1985), sendo responsável por uma importante rota de transferência de energia dos produtores primários aos peixes. Todas essas características tornam a comunidade zooplanctônica elemento-chave para o entendimento das modificações ocorridas em ecossistemas aquáticos particularmente devido à eutrofização.

Esta comunidade é formada por organismos que apresentam diferentes estratégias de desenvolvimento, relacionadas à reprodução e alimentação, possibilitando a colonização de ambientes com distintas características físicas e químicas. A comunidade zooplanctônica é constituída principalmente por protozoários, rotíferos, cladóceros e copépodos (WETZEL, 1983). Os organismos zooplanctônicos apresentam tamanhos de poucos micrômetros até alguns milímetros, fato este, que contribui para a diversidade estrutural do ambiente (BOZELLI \& HUSZAR, 2003).

Entre o microzooplâncton, os Protozoa é um grupo responsável pela transferência da biomassa bacteriana para os metazoários zooplanctônicos (GILRON \& LYNN, 1997; ESTEVES, 1998). O conhecimento das interações entre protozoários e metazoários zooplanctônicos e seu papel em determinar o destino da produção do fitoplâncton e bactérias são essenciais para o entendimento do fluxo de energia nessas cadeias alimentares (SANDERS \& WICKHAM, 1993). Em relação aos rotíferos, sua importância no plâncton é atribuída à alta taxa reprodutiva e conversão da produção primária, de forma que esta possa ser utilizada pelos consumidores secundários, chegando a produzir até $30 \%$ da biomassa total do plâncton (NOGRADY, 1993; ANDREOLI \& CARNEIRO, 2005).

Entre os microcrustáceos, os cladóceros apresentam grande número de espécies, principalmente em regiões litorâneas de lagos e reservatórios, vivendo associados à macrófitas, alimentado-se basicamente de algas e perifíton (SIPAÚBA-TAVARES \& 
ROCHA, 2001; SANTOS-WINIEWISKI et al., 2002). Por outro lado, os copépodos apresentam elevado grau de endemismo com a distribuição geográfica muito restrita por serem mais sensíveis às alterações das variáveis ambientais (MATSUMURA-TUNDISI \& TUNDISI, 1986).

Assim considerando os pressupostos de que a comunidade zooplanctônica é funcionalmente importante em ecossistemas aquáticos e que o uso e ocupação do solo refletem sobre alguns atributos dessa comunidade, o objetivo do presente estudo foi contribuir para o conhecimento da riqueza e abundância do zooplâncton no córrego Santa Maria do Leme a fim de complementar a avaliação da qualidade da água e detectar os efeitos de um ambiente lótico sobre esta comunidade.

\section{Área de estudo}

A Bacia do Tietê-Jacaré pertence ao Sistema Aqüífero Guarani, maior manancial de água doce subterrânea do mundo (CETESB, 2004). Esta bacia, onde está localizada a área urbana do município de São Carlos (2201'04”S; 4753’27”W), apresenta alguns fatores que influenciam diretamente a qualidade dos recursos hídricos, tais como: baixos níveis de tratamento de esgotos domésticos, demandas de água para abastecimento que estão num nível crítico, inundações, superexploração das águas subterrâneas, disposição inadequada de resíduos sólidos e recuperação de antigos lixões (BAIO, 2009).

O município de São Carlos possui uma rica rede hídrica e a cidade se assenta nas cabeceiras de muitos córregos. A cidade é cortada pelos rios Monjolinho, Gregório e Santa Maria do Leme, e pelos córregos, Tijuco Preto, Simeão, Água Quente e Água Fria. O rio Santa Maria do Leme está inserido em área de cerrado que foi desmatada no início da década de 1960 e essa área foi ocupada por fazendas de pastagens. A região da microbacia Santa Maria do Leme a partir da década de 70 foi intensamente urbanizada. As diversas e intensas atividades antropogênicas que foram e ainda são desenvolvidas nesta área, associadas ao aumento populacional, geram poluentes que acabam atingindo os corpos d'água e os sedimentos, promovendo modificações na estruturação dos ecossistemas que podem desencadear processos de desequilíbrio atingindo as comunidades biológicas presentes nesses sistemas. 


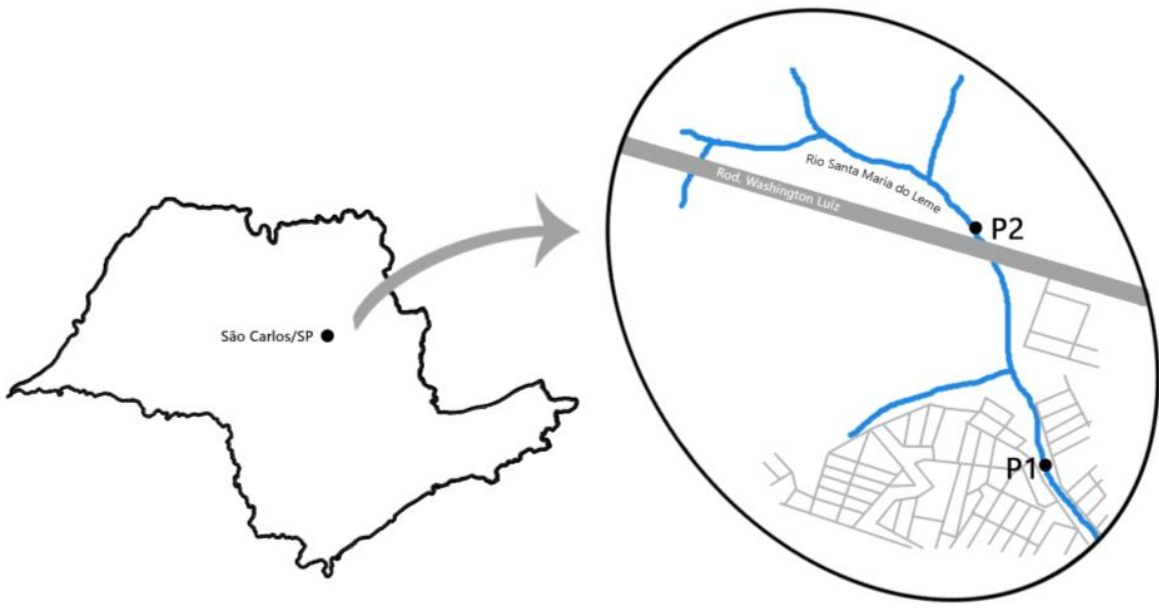

Figura 1. A: Mapa de localização do córrego Santa Maria do Leme no município de São Carlos, São Paulo.

\section{Materiais e Métodos}

\section{Variáveis abióticas}

A coleta foi realizada em outubro de 2012 em dois pontos localizados no córrego Santa Maria do Leme, sendo o ponto P1 ( $21^{\circ} 59^{\prime} 53^{\prime \prime}$ S e $47^{\circ} 54^{\prime} 4^{\prime \prime}$ ) localizado em área urbana e o ponto P2 $\left(21^{\circ} 59^{\prime} 4^{\prime \prime S}\right.$ e $\left.47^{\circ} 54^{\prime} 19^{\prime \prime O}\right)$ em uma região próxima a nascente cujo entorno é formado por pastagens (Figura 2). 

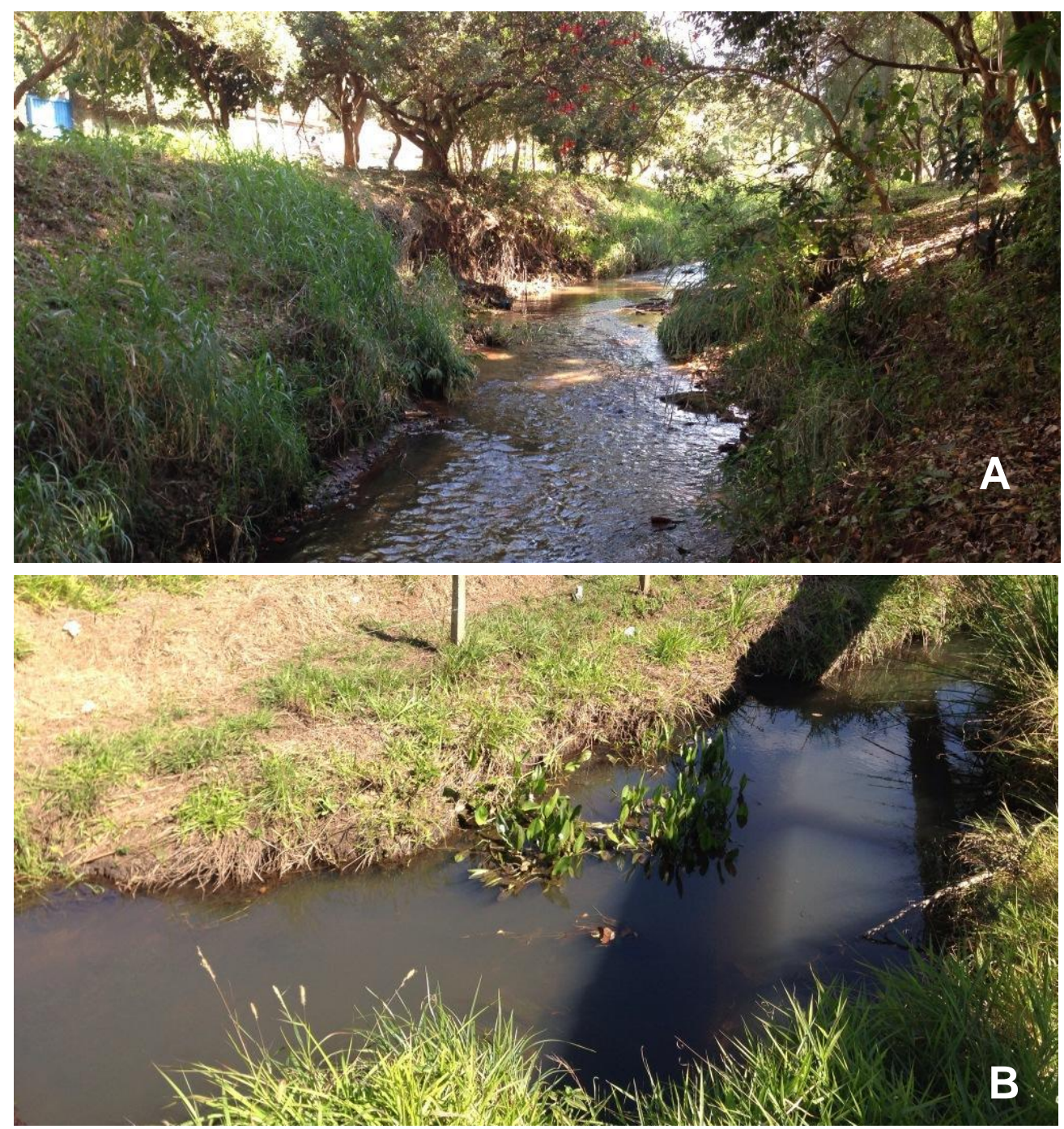

Figura 2. Pontos de coleta no córrego Santa Maria do Leme, São Carlos, SP: A - ponto P1 e B ponto P2.

A temperatura da água, $\mathrm{pH}$, condutividade elétrica e oxigênio dissolvido foram mensurados in situ com uma sonda portátil da marca Horiba ${ }^{\circledR}$, modelo U-10.

\section{Variáveis bióticas}

Os organismos foram coletados com rede de plâncton com diâmetro de $30 \mathrm{~cm} \mathrm{e}$ abertura de malha de $68 \mu \mathrm{m}$, filtrando-se 100 litros de água. Posteriormente foram fixados com formol 4\%. A identificação e quantificação dos microcrustáceos (Cladocera e Copepoda) foram feitas em placas de acrílico quadriculadas sob microscópio 
estereoscópio (aumento até 50x) contando sub-amostras ou, até a amostra inteira, para os organismos raros. Os rotíferos e protozoários foram contados em câmara de Sedgwick-Rafter sob microscópio óptico (aumento até 1000x, com ocular graduada). Para a identificação utilizou-se bibliografia especializada. Com os dados, pode-se calcular a densidade e a abundância das espécies. Os índices de diversidade, dominância e equitabilidade foram calculados utilizando-se o programa estatístico PAST version 1.94 (HAMMER et al., 2001).

\section{Resultados e discussão}

Os valores das características físicas e químicas da água nos pontos de coleta no córrego Santa Maria do Leme estão apresentados na Tabela 1.

Tabela 1: Características físicas e químicas da água nos pontos de coleta no córrego Santa Maria do Leme.

\begin{tabular}{ccc}
\hline & P1 & P2 \\
\hline Temperatura da água $\left({ }^{\circ} \mathbf{C}\right)$ & 22,1 & 21,57 \\
$\mathbf{p H}$ & 5,77 & 5,45 \\
Oxigênio dissolvido $\left(\mathbf{m g ~ L}^{-1}\right)$ & 5,93 & 6,24 \\
Condutividade elétrica $\left(\boldsymbol{\mu S} \mathbf{~ c m}^{-1}\right)$ & 46,0 & 19,0 \\
\hline
\end{tabular}

A temperatura da água foi relativamente alta, como esperado para o período de coleta caracterizado como um período seco. $\mathrm{O}$ pH manteve-se ácido com valores menores que 6,0. A concentração de oxigênio dissolvido registrada está dentro da faixa registrada para ambientes aquáticos urbanos no Brasil. Os valores da condutividade elétrica foram baixos.

Os parâmetros físicos e químicos analisados mostraram que o córrego Santa Maria do Leme é um corpo de água pouco profundo, com águas ácidas devido à presença de grande quantidade de ácidos húmicos, que dá uma coloração escura à água.

Foram identificadas 18 espécies da comunidade zooplanctônica (Tabela 2). No grupo dos protozoários e meroplâncton foram registrados o maior número de espécies (seis cada). Rotifera foi representado por três espécies e Cladocera por duas. A menor riqueza foi registrada para os Copepoda, sendo estes representados apenas pelas formas juvenis (náuplios e copepoditos) da Ordem Cyclopoida. 
Tabela 2: Lista das espécies zooplanctônicas registradas no córrego Santa Maria do Leme.

\begin{tabular}{llc}
\hline & P1 & P2 \\
\hline Cladocera & & \\
Acroperus harpae Baird & & $\mathrm{x}$ \\
Nicsmirnovius cf. fitzparticki (Chien) & & $\mathrm{x}$ \\
\hline Copepoda & & \\
Cyclopoida & & \\
Copepoditos & $\mathrm{x}$ & \\
Náuplios & $\mathrm{x}$ & \\
\hline Rotifera & & \\
Brachionus calyciflorus Pallas & $\mathrm{x}$ & \\
Lecane bulla (Gosse) & $\mathrm{x}$ & \\
Bdelloidea & $\mathrm{x}$ & $\mathrm{x}$ \\
\hline Protozoa & & \\
Astramoeba sp. Vejdovsky & $\mathrm{x}$ & $\mathrm{x}$ \\
Centropyxis aculeata (Ehrenberg) & $\mathrm{x}$ & \\
Ciliata & $\mathrm{x}$ & \\
Difflugia pyriformis Perty & & $\mathrm{x}$ \\
Difflugia sp. Awerintzew & $\mathrm{x}$ & $\mathrm{x}$ \\
Vorticella sp. Ehrenberg & $\mathrm{x}$ & \\
\hline Meroplâncton & & \\
Chironomidae & $\mathrm{x}$ & $\mathrm{x}$ \\
Ephemeroptera & & $\mathrm{x}$ \\
Hydracarina & $\mathrm{x}$ & $\mathrm{x}$ \\
Nematoda & $\mathrm{x}$ & $\mathrm{x}$ \\
Oligochaeta & $\mathrm{x}$ & $\mathrm{x}$ \\
Ostracoda & & $\mathrm{x}$ \\
\hline Riqueza Total & $\mathbf{1 3}$ & $\mathbf{1 2}$ \\
\hline
\end{tabular}

Os representantes dos cladóceros registrados no presente estudo pertencem a Família Chydoridae. As espécies desta família são típicas de região litorânea e encontradas muitas vezes associados aos bancos de macrófitas (SANTOS-WISNIEWSKI et al., 2002).

Para o grupo Copepoda foram registradas apenas as formas juvenis (náuplios e copepoditos) da Ordem Cyclopoida. Alguns trabalhos em água doce revelam a importância das formas jovens de Copepoda na estrutura da comunidade zooplanctônica devido a grande densidade em que ocorrem (ROBERTSON; HARDY, 1984; NUNES et 
al., 1996). Sabe-se que o ciclo de vida dos Copepoda é longo, comparativamente ao dos demais componentes do zooplâncton (Rotifera e Cladocera), o que os tornam suscetíveis a uma alta taxa de mortalidade antes de atingirem o estágio adulto.

Rotifera foi representado apenas por duas espécies, Brachionus calyciflorus e Lecane bulla, sendo o segundo grupo holoplanctônico em termos de riqueza de espécies. Esta maior riqueza de rotíferos é um padrão recorrente em ambientes aquáticos tropicais (MATSUMURA-TUNDISI, 1999). Rocha et al. (1995) apresentaram uma relação da riqueza de 22 diferentes ecossistemas de água doce e afirmaram que a riqueza de rotíferos é amplamente dependente das famílias Lecanidae e Brachionidae, semelhante ao observado no presente estudo. As famílias Brachionidae e Lecanidae encontradas no córrego Santa Maria do Leme apresentam elevada riqueza espécies em regiões tropicais.

Os protistas possuem papel ecológico muito importante em sistemas naturais, pois constituem um dos principais componentes dos ciclos biogeoquímicos globais, regulando o suprimento e a demanda de carbono orgânico, a ciclagem de nutrientes e o balanço de gás carbônico e oxigênio dentro e entre os ecossistemas (SILVA, 2008). No presente estudo, os organismos deste grupo foram os mais diversos e abundantes, no entanto, Auer e Arndt (2001) relatam que existe pouca informação sobre a influência do estado trófico do ambiente na estrutura taxonômica e na distribuição dos protistas em sistemas naturais.

Protozoa são raramente incluídos em estudos da comunidade zooplanctônica de água doce. No entanto, neste trabalho optou-se em incluir os protozoários, pois os pontos amostrados são de ambientes lóticos e é relatado na literatura que nestes ambientes Protozoa podem ultrapassar em termos de abundância os Rotifera e microcrustáceos (PERBICHE-NEVES \& SERAFIM-JÚNIOR, 2007). Já em ambientes lênticos os cladóceros, copépodos e rotíferos são considerados os mais importantes em termos de densidade, biomassa, produção, grazing e ciclagem de nutrientes (HUTCHINSON, 1967).

As espécies de protozoários registradas foram principalmente pertencentes as tecamebas (Centropyxis aculeata, Difflugia pyriformis e Difflugia sp.), pois estes organismos não estouram com o formol e não passam pela malha da rede de $68 \mu \mathrm{m}$. É relatado na literatura que as amebas testáceas pertencem ao grupo dos Protistas de vida livre mais heterogêneo e polifilético. Em ambientes de águas correntes a riqueza deste grupo é maior (LANSAC-TÔHA et al., 2000). 
O padrão dos valores de densidade da comunidade zooplanctônica seguiu a tendência da riqueza, com Protozoa e Rotifera representando os maiores valores, sendo que no ponto $\mathrm{P} 1$ estes dois grupos representaram $99 \%$ da densidade total do zooplâncton (Tabela 3 e Figuras 3 e 4). Estes grupos são considerados $r$ estrategistas e possuem menores tamanhos em comparação aos demais representantes da comunidade zooplanctônica. Geralmente, ambientes com curtos tempo de residência favorecem o desenvolvimento desses indivíduos, como observado no reservatório do Broa (MATSUMURA-TUNDISI; TUNDISI, 1986); na represa de Barra Bonita (MATSUMURATUNDISI et al., 1990) e no reservatório do Monjolinho (OKANO, 1994). Outro fato relevante para esses dois grupos está relacionado à eutrofização. Alguns padrões têm sido observados em corpos d'água brasileiros onde Rotifera e Protozoa são registrados em ambientes eutróficos enquanto Copepoda e Cladocera são mais abundantes que os demais em ambientes oligotróficos (MATSUMURA-TUNDISI, 1999).

O ponto P1 se localiza em área urbana e consequentemente pode estar sofrendo alterações na qualidade da água, resultado que corrobora a presença da Ordem Cyclopoida e do Rotífera Bdelloidea nesse local. Esses táxons toleram condições de poluição e são registrados em ambientes impactados (MATSUMURA-TUNDISI et al., 1990).

Tabela 3: Densidade (ind $\mathrm{m}^{-3}$ ) das espécies zooplanctônicas registradas no córrego Santa Maria do Leme.

\begin{tabular}{lcc}
\hline & P1 & P2 \\
\hline Cladocera & & \\
Acroperus harpae Baird & 13 \\
Nicsmirnovius cf. fitzparticki (Chien) & 38 \\
Total Cladocera & 50 \\
\hline Copepoda & \\
Cyclopoida & \\
Copepoditos & 15 \\
Náuplios & 270 \\
Total Copepoda & $\mathbf{2 8 5}$ \\
\hline Rotifera & \\
Brachionus calyciflorus Pallas & 45 \\
Lecane bulla (Gosse) & 1350 \\
Bdelloidea & 8100 \\
Total Rotifera & 339 \\
\hline
\end{tabular}




\begin{tabular}{lcc} 
Protozoa & & \\
Astramoeba sp. Vejdovsky & 9450 & 1130 \\
Centropyxis aculeata (Ehrenberg) & 5400 & \\
Ciliata & 1350 & \\
$\begin{array}{l}\text { Difflugia pyriformis Perty } \\
\text { Difflugia sp. Awerintzew }\end{array}$ & \multicolumn{1}{c}{1130} \\
Vorticella sp. Ehrenberg & 1350 & 13 \\
Total Protozoa & 13500 & \\
\hline Meroplâncton & $\mathbf{3 1 0 5 0}$ & $\mathbf{2 2 7 3}$ \\
Chironomidae & & \\
Ephemeroptera & 45 & 339 \\
Hydracarina & & 113 \\
Nematoda & 27 & 113 \\
Oligochaeta & 15 & 23 \\
Ostracoda & 45 & 16 \\
Total Meroplâncton & & 23 \\
\hline Total geral & $\mathbf{1 3 2}$ & $\mathbf{6 2 6}$ \\
\hline & $\mathbf{4 0 9 6 2}$ & $\mathbf{3 2 8 8}$ \\
\hline
\end{tabular}

O microzooplâncton (rotíferos e protozoários) dominou sobre os microcrustáceos. Esse padrão de distribuição particular dos grupos zooplanctônicos é típico de ecossistemas de água doce e refletem as relações entre os organismos planctônicos na pirâmide trófica.

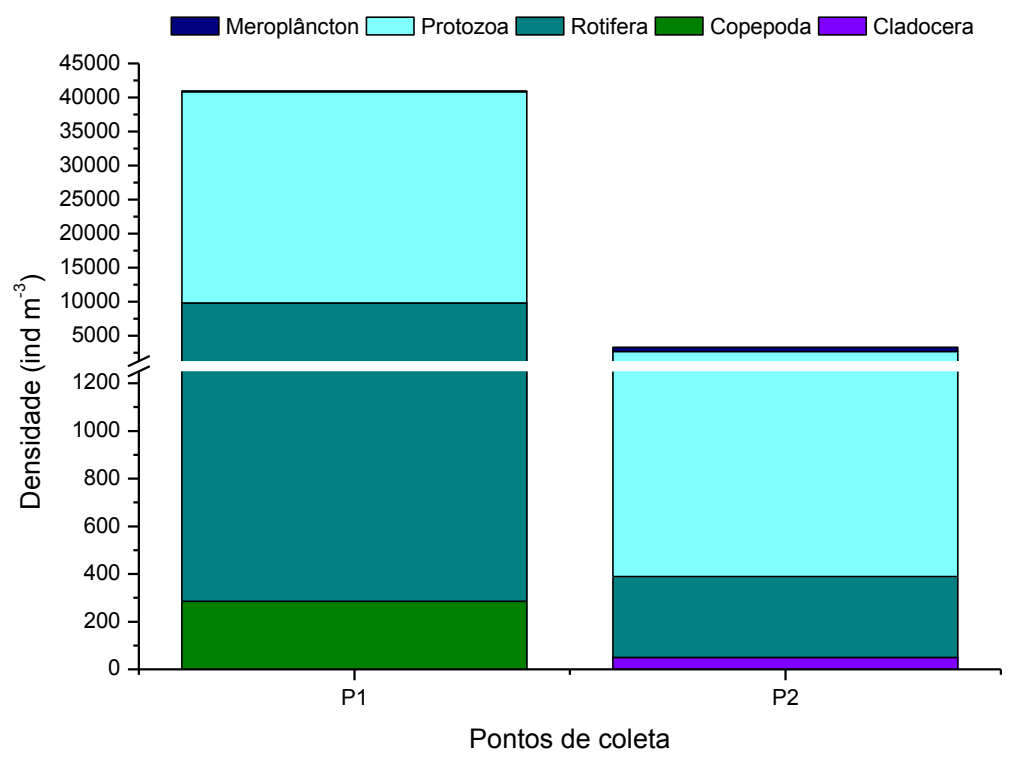

Figura 3. Densidade (ind. $\mathrm{m}^{-3}$ ) dos grupos zooplanctônicos nos pontos de coleta do córrego Santa Maria do Leme. 
A grande abundância de protozoários e rotíferos nos pontos amostrados pode estar relacionada principalmente com as características do ambiente (Figura 4). Em locais de mistura pode ocorrer a ressuspensão dos sedimentos no fundo, rico em matéria orgânica e bactérias decompositoras o que torna estes ambientes ótimos substratos para 0 desenvolvimento destes grupos de animais.

Foi observada a presença de $A$. harpae e $N$. cf. fitzpatricki no ponto $\mathrm{P} 2$ em baixas densidades. Nesse ponto, durante a coleta, havia de macrófitas aquáticas, favorecendo desta forma o estabelecimento destes organismos que são típicos de regiões litorâneas ricas em macrófitas (SANTOS-WISNIEWISKI et al., 2002).

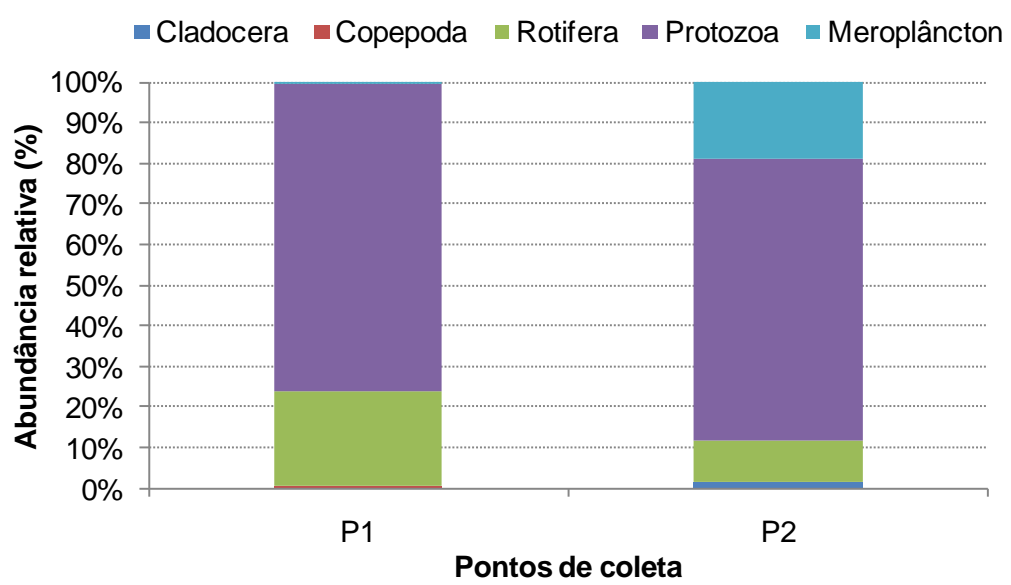

Figura 4. Abundância relativa (\%) dos grupos zooplanctônicos nos pontos de coleta do córrego Santa Maria do Leme.

Pinto-Coelho et al. (1999) verificaram os efeitos da eutrofização na estrutura das comunidades planctônicas no reservatório da Pampulha em Belo Horizonte, utilizando diferentes índices de diversidade, os resultados obtidos mostraram que o índice de Shannon foi mais adequado para estudos de comunidades mais eficientemente amostradas. Durante este estudo, o índice de diversidade e de equitabilidade da comunidade zooplanctônica (Figura 5) nos pontos do córrego Santa Maria do Leme foram baixos quando comparados a outros estudos realizados em outros ambientes lóticos (PEREIRA et al., 2011). Como consequência desse resultado o índice de dominância foi baixo $(<0,26)$. Segundo Rosso (1996) o índice de Shannon-Wiener, já tradicionalmente 
designado como índice de Shannon, é a medida de diversidade mais consagrada em estudos ecológicos.

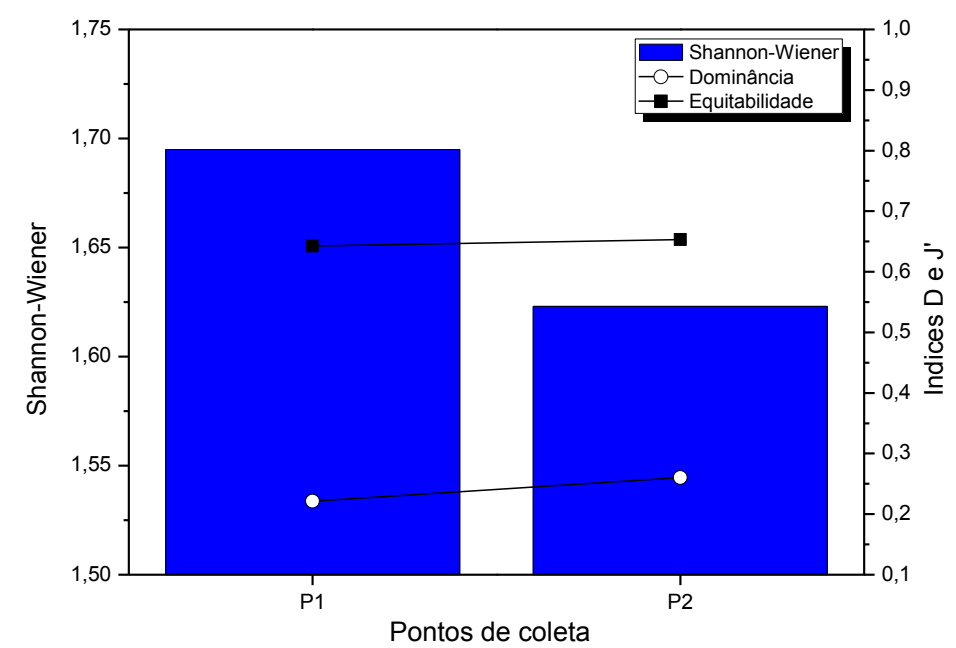

Figura 5. Índices de diversidade (Shannon-Wienner), dominância (D) e equitabilidade (J') da comunidade zooplanctônico nos pontos de coleta do córrego Santa Maria do Leme.

\section{Conclusões}

A análise da comunidade zooplanctônica do córrego Santa Maria do Leme revelou um padrão diferenciado na abundância e diversidade de espécies para os diderentes grupos taxonômicos. Os protozoários e rotíferos dominaram tanto em termos de riqueza quanto em densidade. O micro-hábitat proporcionado pela instabilidade dos locais garantiu uma maior quantidade de matéria orgânica em suspensão, favorecendo o microzooplâncton.

\section{Referências Bibliográficas}

ANDREOLI, C. V.; CARNEIRO, C. Gestão integrada de mananciais de abastecimento eutrofizados. Curitiba: Sanepar/ FINEP, 2005. 500 p.

AUER, B.; ARNDT, H. Taxonomic composition and biomass of heterotrophic flagellates in relation to lake trophy and season. Freshwater Biology, v. 46, n.7, p. 959-972, 2001. 
BAIO, J. A. F. Avaliação da contaminação nos principais corpos d'água do município de São Carlos/SP. 2009.111 f. Tese (Mestrado em Ciências). Universidade Federal de São Carlos, São Carlos. 2009.

BOZELLI, R. L.; HUSZAR, V. L. M. Comunidades fito e zooplanctônicas continentais em tempo de avaliação. Limnotemas. Sociedade Brasileira de Limnologia, 2003.

CETESB, Relatório de qualidade das águas interiores do estado de São Paulo. 2004. CETESB, São Paulo.

ESTEVES, F. A. Fundamentos de limnologia. Rio de Janeiro: Interciência/FINEP, 1998. $574 \mathrm{p}$.

GILRON, G. L.; LYNN, D. H. Ciliated protozoa as test organisms in toxicity assessments. In: WELLS, P. G.; LEE, K.; BLAISE, C. (Eds.). Microscale testing in aquatic toxicology: advances, techniques, and practice. Boca Raton: CRC Press, 1997. p. 323-336.

HAMMER, U. T.; HARPER, D.; RYAN, P. PAST: Paleontological statistics software package for education and data analysis. Paleontological Electronic, v. 4, n. 1, 9 p. 2001

HUTCHINSON, G. E. A Treatise on Limnology. II. Introduction to lake biology and their limnoplankton. New York: John Wiley \& Sons, 1967. 1115 p.

LANSAC-TÔHA, F. A., VELHO, L. F. M., ZIMMERMANN-CALLEGARI, M. C., BONECKER, C. C. On the occurrence of testate amoebae (Protozoa, Rhizopoda) in Brazilian inland waters. I. Family Arcellidae. Acta Scientiarum, vol. 22, no. 2, p. 355-363, 2000.

MAIA-BARBOSA, P. M.; BRITO, S.; RIETZLER, A. C.; ESKINAZI-SANT'ANNA, E. M. S. Diversidade do Zooplâncton de Minas Gerais. Ciência Hoje ,38: 67- 69, 2006. 
MATSUMURA-TUNDISI, T. Diversidade de zooplâncton em represas do Brasil. In: HENRY, R. (Ed.). Ecologia de reservatórios: estrutura, função e aspectos sociais. Botucatu: FUNDBIO/FAPESP, 1999. p. 39-54.

MATSUMURA-TUNDISI, T.; TUNDISI, J. Preliminary studies in a lacustrine environment. I. Preliminary data on zooplankton ecology of Broa Reservoir. Oecology, v. 25, p. 265-270, 1986.

MATSUMURA-TUNDISI, T.; LEITÃO, S. N.; AGUENA, L. S.; MIYAHARA, J. Eutrofização da represa de Barra Bonita: estrutura e organização da comunidade de Rotífera. Revista Brasileira de Biologia, v. 50, n. 4, p. 923-935, 1990.

NEGREIROS, N. F.; ROJAS, N. E. T.; ROCHA, O.; SANTOS-WISNIEWSKI, M. J. Composition, diversity and short-term temporal fluctuations of zooplankton communities in fish culture ponds (Pindamonhangaba), SP. Brazilian Journal of Biology, v. 69, p. 785-794, 2009.

NOGRADY, T. Rotifera: biology, ecology and systematics. Haia: SPB Academic Publishing, vol. 1. 142 p, 1993.

NUNES, M. A.; LANSAC - TÔHA, F. A.; BONECKER, C. C.; ROBERTO, M. C.; RODRIGUES, L. Composição e abundância do zooplâncton de duas lagoas do Horto Florestal Dr. Luiz Teixeira Mendes, Maringá, Paraná. Acta Limnologica Brasiliensia, v. 8, p. 207-219, 1996.

OKANO, W. Y.. Análise da estrutura e dinâmica populacional da comunidade zooplanctônica de um reservatório artificial (Represa do Monjolinho, São Carlos - SP). 1994. 128 p.Tese de Doutorado. Universidade Federal de São Carlos, São Carlos, SP, Brasil. 1994.

PERBICHE-NEVES, G.; SERAFIM-JÚNIOR, M. Zooplâncton de um trecho do rio 
Laranjinha (Bacia do rio Paranapanema), Estado do Paraná, Brasil. Estud. Biol., vol. 29, $n^{\circ}$ 68/6, p. 257-268, 2007.

PEREIRA, A. P. S.; VASCO, A. N.; BRITTO, F. B.; MÉllO-JúNIOR, A. V.; NOGUEIRA, E. M. S. Biodiversidade e estrutura da comunidade zooplanctônica na Sub bacia Hidrográfica do Rio Poxim, Sergipe, Brasil. Revista Ambiente \& Água - An Interdisciplinary Journal of Applied Science, v. 6, n. 2, 2011.

PINTO-COELHO, R. M.; COELHO, M. M.; ESPÍRITO SANTO, M. M.; CORNELISSEN, T. G. Efeitos da eutrofização da comunidade planctônica na Lagoa de Pampulha, Belo Horizonte - MG. p. 551-572. In: HENRY, R. (Ed.). Ecologia de reservatório: estrutura, função e aspectos sociais. Botucatu: FUNDIBIO/FAPESB, 1999.

ROBERTSON, B. A.; HARDY, E. R. Zooplankton of Amazonian lakes and rivers. The Amazon. Monographic Biological, v. 56, p. 337-352, 1984.

ROCHA, O.; SENDACZ, S.; MATSUMURA-TUNDISI, T. Composition, biomass and productivity of zooplankton in natural lakes and reservoirs of Brazil. In: TUNDISI, J. B.; BICUDO, C. E.; MATSUMURA-TUDISI, T. (Eds.). Limnology in Brazil. Rio de Janeiro: ABC/SLB. p.151-165. 1995.

ROCHE, K. F.; ROCHA, O. Aspectos de predação por peixes e, lagos e represas, com enfoque na planctivoria. In: ROCHE, K.F.; ROCHA, O. Ecologia trófica de peixes com ênfase na planctivoria em ambientes lênticos de água doce no Brasil. 1 ed. São Carlos: Rima. 2005, p.1-24.

ROSSO, S. Amostragem, repartição espacial e diversidade/dominância de comunidades de costões rochosos: uma abordagem metodológica. Laboratório de Ecologia Marinha/USP. 1996. 30 p.

SANDERS, R. W.; WICKHAM, S. A. Planktonic protozoa and metazoan: predations, food quality and population control. Mar. Microb. Food Webs, v. 7, n. 2, p. 197-223, 1993. 
SANTOS-WISNIEWSKI, M. J.; ROCHA, O.; GÜNTZEL, A. M.; MATSUMURA-TUNDISI, T. Cladocera Chydoridae of high altitude water bodies (Serra da Mantiqueira), in Brazil. Revista Brasileira de Biologia = Brazilian Journal of Biology, v. 62, n. 4a, p. 681-687, 2002.

SANTOS, R. M., ROCHA, G. S., ROCHA, O. \& SANTOS-WISNIEWSKI, M. J. Influence of net cage fish cultures on the diversity of the zooplankton community in the Furnas hydroelectric reservoir, Areado, MG, Brazil. Aquaculture Research, vol. 40, p. 753-776, 2009.

SILVA, M. B. Assembléias de amebas testáceas (Amoebozoa: Rhizopoda) associadas a rizosfera de Eichhornia crassipes (Martius) Solomons (Pontederiaceae) no Rio Cachoeira, Bahia. 2008. 115 f. Tese (Mestrado em Sistemas Aquáticos Tropicais) - Universidade Estadual de Santa Cruz, Ilhéus, BA. 2008.

SIPAÚBA-TAVARES, L. H.; ROCHA, O. Produção de plâncton (fitoplancton e zooplancton) para alimentação de organismos aquáticos. 3. ed. São Carlos: Rima, 2001. $106 \mathrm{p}$.

SORANNO, P. A.; CARPENTER, S. R.; HE, X. 1985. Zooplankton biomass and body size. Pp 172-188. In: Carpenter, S. R.; Jitchell, F. (Eds.). The Trophic Cascade in Lakes. London: Cambridge Pergamon Press, 1985, 381 p.

WETZEL, R. G. Limnologia. 2. ed. Lisboa: Fundação Calouste Gulbenkian, 1983, 1110 p. 